\title{
Mudanças na Administração Municipal: Possibilidades de uma Formação Político-Organizacional
}

\author{
Maria Ceci A. Misoczky
}

\section{Resumo}

Este artigo explora, a partir de dois casos, práticas inovadoras, reconhecidas por terem expandido tanto a participação popular no processo decisório quanto direitos sociais - o Programa de Saúde Mental de Belo Horizonte rompe com padrões de relações sociais baseadas no preconceito, estigmatização e exclusão; o Orçamento Participativo de Porto Alegre rompe com padrões de definição do gasto público baseados no clientelismo e patrimonialismo. O objetivo é compreender até que ponto o desenvolvimento de políticas inclusivas e a relação entre cidadania ativa e governo local estão criando uma formação político-organizacional neste nível de governo. Para isto consideram-se duas formações: a burocrática-tradicional e a político-organizacional. No caso de Belo Horizonte encontram-se muitas inovações dentro da administração pública, enquanto em Porto Alegre esta não é a tendência dominante. Algumas diferenças históricas e políticas na origem dos dois projetos, podem ter influenciado o seu desenvolvimento. Discute-se, ainda, que as mudanças já ocorridas podem induzir outras inovações nestas organizações públicas.

Palavras-chaves: formação burocrática tradicional; formação político-organizacional; projeto de saúde mental de Belo Horizonte; orçamento participativo de Porto Alegre.

\section{Abstract}

This article explores two case studies of innovative practices in Brazil, acknowledged as having extended both popular participation in the decision making process and social rights - the Mental Health Project of Belo Horizonte breaks with the usual patterns of social relation based on prejudice, stigmatisation and exclusion, while the Participatory Budget of Porto Alegre breaks with patterns based on clientelisc and patrimonialistic practices in the definition of public expenditure. The aim is to understand to what point the development of inclusive policies and the relationship between active citizenship and local government are creating a political organizational formation at this level of government. In order to identify organizational changes in the case-studies, we can consider two formations: the traditional bureaucratic and the political organisational. In the case of Belo Horizonte it was identified the existence of many innovative practices inside the public administration, while in Porto Alegre this is not the predominant trend. Some of the historical and political differences in the origin of the two projects that could have influenced their outcomes are explored. Possible developments in the projects and changes (including societal ones) already produced that may induce further innovations in these public organizations are considered.

Key words: traditional bureaucratic formation; political organizational formation; mental health project of Belo Horizonte; participatory budget of Porto Alegre. 


\section{INTRODUÇÃO}

A extensão de direitos sociais, com a decorrente explosão de demandas e saturação da agenda governamental, é apontada por Santos (1994) como fator potencialmente desestabilizador das instituições democráticas. Juntamente com a inércia decisória e o transbordamento da participação social, a explosão de demandas comporia o quadro de causas da crise de governabilidade brasileira. Para resolvê-la alguns autores afirmam que seriam necessários novos freios institucionais, voltados para controlar o igualamento de direitos, a manifestação das minorias, a proliferação de organizações e a multiplicidade de demandas (Diniz, 1997). Haggard e Kaufman (1993), analisando estes fatores como dificuldades para a execução de programas de estabilização econômica, recomendam o confinamento da tecnocracia em agências protegidas dos embates da política competitiva e das pressões da sociedade.

Outra abordagem considera estas análises deficientes, por serem reducionistas, terem um viés tecnocrático e uma perspectiva elitista (Diniz, 1997). Em oposição lembra que o grande contingente populacional que vive em condições de destituição social e política, na ausência de direitos e de acesso a serviços básicos, inviabiliza o exercício da cidadania e a vigência da democracia. Assim, o enfoque central para pensar a reforma do Estado deve ser como compatibilizar eficiência com aprimoramento da democracia. "Aumentar a governabilidade de uma ordem democrática implica não apenas melhorar o desempenho da máquina burocrática, mas ampliar a responsabilidade do Estado em face das metas coletivas e das demandas sociais” (Diniz, 1997, p. 47).

Esta abordagem implica, portanto, a redefinição do conceito dominante de autonomia estatal e do modelo de gestão pública a ele associado. É nesta perspectiva que Azevedo e Andrade (1997) criticam a proposta de reforma do Estado brasileiro. Segundo os autores, esta proposta contém traços tradicionais, repetindo padrões que têm marcado a história política e institucional do país. Um deles é o caráter geral e homogêneo pretendido para resolver os problemas da Administração Pública nas três esferas de governo. Azevedo e Andrade (1997, p. 74) perguntam "por que não conceder aos estados e municípios as condições [...] para equacionar nos termos que melhor lhes convier sua forma e estrutura de atuação?”, já que isto favoreceria a inovação e permitiria uma gama considerável de experiências alternativas.

Tais experiências podem ser analisadas, no nível interorganizacional, a partir de 
dois referenciais que se complementam. Junqueira, Inojosa e Komatsu (1998) definem intersetorialidade como a articulação de setores e experiências no planejamento, na realização e na avaliação de ações, como forma de alcançar um efeito sinérgico em situações complexas, com vistas ao desenvolvimento social e à superação da exclusão social. Loiola e Moura (1997), por sua vez, revisam os diferentes sentidos de rede. Ao tratar especificamente das políticas públicas desenvolvidas no âmbito local, afirmam que a rede permite articular os diversos atores da sociedade civil e do Estado em torno de uma ação pública. Junqueira (1998, p. 95) chama de rede a "interação de pessoas, instituições, famílias, municípios e estados, mobilizados em função de uma idéia abraçada coletivamente”. É uma maneira de superar os limites da ação por meio da integração de diferentes conhecimentos e práticas, uma construção coletiva que se define na medida em que se realiza.

Fischer (1997) afirma que as características que reúnem organizações de natureza diferenciada, em articulações por propósitos comuns, são a diversidade e a transição para novas formas organizacionais, estruturalmente leves. Destas articulações decorrem novos designs organizacionais, que se configuram visualmente como fóruns, conselhos, grupo tarefa, consórcios etc. Este modelo autodesenhado tem "hierarquias planas organizadas em torno de processos transversais, deixando espaços para fluxos de informação e conhecimento, diálogo e ação concentrada" (Fischer, 1997, p. 18). Ao governo, uma das peças nesta articulação, cabe "liderar o processo em muitos momentos, mas também partilhar, delegar, interagir” (Fischer, 1997, p. 15).

Santos (1998) chama a atenção para três tipos de relações possíveis das organizações da sociedade com o Estado: as organizações da sociedade enquanto instrumento do Estado, enquanto amplificadoras de programas estatais, ou enquanto parceiras nas estruturas de poder e coordenação. Este autor afirma, ainda, que o terceiro tipo aponta uma "nova forma de organização política, mais vasta que o Estado, da qual o Estado é o articulador e que integra um conjunto híbrido de fluxos, redes e organizações, em que se combinam e interpenetram elementos estatais e não estatais, nacionais, locais e globais” (Santos, 1998, p. 13).

Este aspecto de transformação da organização do Estado é exatamente o que nos interessa nesse estudo, ou seja, busca-se compreender até que ponto o desenvolvimento de políticas inclusivas de grupos populacionais desprovidos de direitos de cidadania, e a relação entre cidadania ativa e administração municipal, estão configurando uma formação político-organizacional no interior deste nível de governo. A expressão formação político-organizacional se refere a estruturas e dinâmicas organizacionais de novo tipo, decorrentes de mudanças necessárias para que as instâncias de poder e de coordenação das políticas públicas, no nível interno/operacional do governo municipal, se tornem permeáveis às organizações da sociedade. 


\section{Até que Ponto...}

A formulação do tema central deste estudo, utilizando as palavras até que ponto se baseia na concepção de que processos de mudanças não são centrípetos ou de aspecto único, nem se desenvolvem de forma homogênea até atingir um novo estado, ou seja, a organização é vista não como sistema que sempre atingirá um estado de equilíbrio, mas como um cenário de instabilidade potencial. Da mesma forma, o desenvolvimento de políticas inclusivas e as parcerias com a sociedade também se dão de forma instável, já que ser e exercer a cidadania é processo que se "atualiza na medida em que as pessoas vão experimentando relações e percebem que seu saber e sua experiência têm importância e são respeitados” (Junqueira, Inojosa e Komatsu, 1998, p. 75).

Refletindo sobre processos de mudança nas sociedades contemporâneas, Heller e Fehér (1998) defendem que, em um contexto de descentralização/fragmentação, as ações transformadoras podem ser empreendidas em diferentes esferas da sociedade. Trazendo as formulações destes autores para o foco da Administração Pública municipal, podemos dizer que mudanças podem acontecer em qualquer uma das suas partes, independentemente de haver correspondência em outras, e em alguns aspectos apenas, independentes de outros. Por exemplo, o aumento da autonomia, condição necessária para que ocorram mudanças, não elimina a divisão funcional do trabalho; a lógica da decisão participativa pode ser dominante, mas não elimina completamente decisões hierárquicas com motivação econômica ou legal. Este raciocínio nos leva a concluir que as mudanças ocorrem em diferentes aspectos e com diferentes ritmos de implementação, devendo, portanto, ser tratadas em termos relativos, como uma relação do novo com o tradicional. Parafraseando Santos (1995), o novo é composto, em parte, por novas combinações e novas escalas do que já existe.

Outro fator que leva a esta abordagem é o reconhecimento de que processos de mudança sempre implicam resistências que, por sua vez, também serão de diferentes grupos, a respeito de diferentes aspectos e com diferentes intensidades (Junqueira, Inojosa e Komatsu, 1998).

\section{Cidadania Ativa, Administração Ativa}

Como lembra Arendt (1998), os homens não nascem iguais, tornam-se iguais como membros de uma coletividade em virtude de decisões que garantem a todos direitos iguais. Este tornar-se iguais implica, no contexto de sociedades marcadas por desigualdade, que se realize a transposição da concepção de cida- 
dania passiva e privada para a de cidadania ativa e pública (Turner, 1990); além disso, se relaciona com a prática democrática, com a possibilidade de superar divisões e diferenças por meio do reconhecimento da legitimidade dos conflitos e da ação política, de organizações da sociedade, na luta pela efetivação de direitos existentes ou pela criação de novos.

A concepção de cidadania ativa implica que os sujeitos tenham responsabilidades com a comunidade a que pertencem; é valorizada, porque permite que os cidadãos exerçam seus poderes de ação, desenvolvam suas capacidades de julgamento e consigam, pela ação organizada, algum nível de eficácia política (Fernández e Barrientos, 2000).

Scherer-Warren (1999, p.14-15) relaciona a ação organizada, coletiva e reativa aos contextos histórico-sociais nos quais se insere, com movimentos sociais e identifica três formas pelas quais essas reações podem ocorrer: "denúncia, protesto, explicitação de conflitos, oposições organizadas”; “cooperação, parcerias para resolução de problemas sociais, ações de solidariedade"; ou "construção de uma utopia de transformação, com a criação de projetos alternativos e de propostas de mudança". A autora esclarece, ainda, que "um mesmo movimento pode desenvolver simultaneamente estas três dimensões - contestadora, solidarística e propositiva”.

Por outro lado, considerar organizações e práticas da Administração Pública que sejam democratizadoras e socialmente inclusivas, compreende pensar aquelas em que os cidadãos são vistos como membros plenos da comunidade política, tendo acesso a direitos e exercitando-os; as que promovem (respeitando a sua autonomia) a organização da população em torno de temas de interesse comum; as que incluem o controle social sobre a gestão, o debate amplo e informado sobre questões de governo, e que abrem à população as decisões sobre estas questões. Como Fernández e Barrientos (2000, p.10) frisam, trata-se de práticas que não buscam somente melhorar a eficiência administrativa das diferentes organizações públicas, mas que incorporam no seu processo de gestão a dimensão ativa da cidadania, isto é, “que facilitam as iniciativas e responsabilidades de todos os envolvidos [...], estabelecendo pontes entre Estado e sociedade civil”.

King e Stivers (1998) defendem, ainda, que é por meio desta aproximação entre Administração Pública e cidadãos que pode ser restabelecida a confiança no governo. Sob a expressão “o governo somos nós”, os autores propõem uma Administração Pública democrática, que envolva a cidadania ativa. "Por administração ativa entendemos não um fortalecimento do poder administrativo, mas o uso da autoridade discricionária para criar o trabalho colaborativo com os cidadãos. A administração ativa é aquela que atua criativamente para direcionar prerrogativas administrativas para a cidadania ativa” (King e Stivers, 1998, p. 195). No entanto 
construir estas parcerias requer que os membros das burocracias públicas abandonem a perícia profissional como base exclusiva da sua ação, e aceitem que a experiência vivida dos cidadãos também oferece uma base legítima para procedimentos coletivos de decisão e implementação de políticas públicas.

\section{Formação Burocrático-Tradicional x Formação Político- OrganizaCIONAL}

O termo formação é usado em decorrência das recomendações de Cooper e Burrell (1988), segundo as quais uma análise da produção da organização deve assumir que elas são formadas e, simultaneamente, atuam para estruturar relações. A explicitação do aspecto político se deve a uma visão da Administração Pública em que esta deve deixar de ser o que Arendt (1998) chama de "governo de ninguém”, por causa do pretenso anonimato das decisões e da falta de responsabilidade pessoal, e passe a ser uma organização em que os compromissos com setores e interesses sejam claramente expressos.

A seguir são apresentados os aspectos que apóiam a compreensão da formação burocrático-tradicional e da formação político-organizacional, entendidas como tipos-ideais (no sentido weberiano).

Segundo Inojosa (1998, p. 39), do ponto de vista da modelagem, “a organização do aparato tradicional dos três níveis de governo no Brasil responde ao paradigma da teoria clássica da administração”. As estruturas organizacionais ainda se apresentam, em geral, com formato piramidal, composto de vários escalões hierárquicos, e departamentalizadas setorialmente por disciplinas ou áreas de especialização. "A essas características soma-se um conjunto de práticas de organização do trabalho, como centralização decisória, planejamento normativo, dicotomia entre planejamento e execução (planos de papel), sigilo e ocultação de informações, formalização excessiva (grande produção de papéis que circulam em rotas horizontais e verticais, para receberem, no mais das vezes, meros encaminhamentos), e distanciamento do cidadão e mesmo do usuário, dificultando o controle social”. Segundo a autora, embora este modelo não seja privativo do setor público, ele parece particularmente resistente nas organizações governamentais.

Como forma de sintetizar os aspectos que permitem identificar a formação burocrático-tradicional, foram utilizados os princípios de Fayol (1954) e os atributos da burocracia, segundo Weber (1997), além do aporte das formulações de Guerreiro Ramos (1983).

Buscando compreender aspectos da formação político-organizacional, foi feita 
uma adaptação de contribuições de diversos autores (Cooper, 1984; Clegg, 1990; Boje e Dennehy, 1993; Santos, 1995; Matus, 1996; Fischer, 1997; Loiola e Moura, 1997; Thieleman, 1997; Farah, 1998; Motta, 1998; Soares e Gondim, 1998; Tendler, 1998), resultando no que se apresenta no Quadro 1.

\section{Quadro 1: Atributos da Formação Burocrático-Tradicional e da Formação Político-Organizacional}

\begin{tabular}{|c|c|}
\hline Formação burocrático-tradicional & Formação político-organizacional \\
\hline $\begin{array}{l}\text { Centro claro de poder - planejamento centralizado, } \\
\text { sem a participação dos executores e dos usuários. }\end{array}$ & $\begin{array}{l}\text { Centros difusos de poder - planejamento } \\
\text { descentralizado, incluindo a participação dos } \\
\text { executores e dos usuários. }\end{array}$ \\
\hline $\begin{array}{l}\text { Estruturas hierárquicas rígidas }- \text { liderança } \\
\text { centralizada nos diversos níveis hierárquicos } \\
\text { (unidade de comando) e orientada para o } \\
\text { cumprimento de metas definidas de modo } \\
\text { normativo. }\end{array}$ & $\begin{array}{l}\text { Estruturas fluidas flexíveis - liderança } \\
\text { descentralizada com uma ética voltada para servir os } \\
\text { usuários em uma rede de relacionamentos, orientada } \\
\text { por uma imagem-objetivo em um contexto histórico } \\
\text { social. }\end{array}$ \\
\hline Ações padronizadas, baseadas em papéis e normas. & $\begin{array}{l}\text { Ações auto-reguladas, criadas a partir das } \\
\text { necessidades da imagem-objetivo e das mudanças } \\
\text { em curso. }\end{array}$ \\
\hline $\begin{array}{l}\text { Divisão do trabalho - redução do número de tarefas } \\
\text { ao menor número possível, aumentando a eficiência } \\
\text { pela repetição rápida e simples do esforço. }\end{array}$ & $\begin{array}{l}\text { Multiplicação do trabalho - aumento do número de } \\
\text { tarefas desenvolvidas ao máximo possível, } \\
\text { aumentando a eficiência ao engendrar um sistema } \\
\text { complexo e flexível. }\end{array}$ \\
\hline $\begin{array}{l}\text { Setorialidade - operação fragmentada com base na } \\
\text { especialização do saber e em programas normativos } \\
\text { verticalizados. }\end{array}$ & $\begin{array}{l}\text { Intersetorialidade }- \text { articulação de saberes } \mathrm{e} \\
\text { experiências no planejamento, realização e } \\
\text { avaliação de ações interligadas, se refere aos } \\
\text { problemas da população e seu equacionamento. }\end{array}$ \\
\hline As metas são a manutenção e o crescimento. & $\begin{array}{l}\text { A meta é a mudança, como um processo consciente } \\
\text { de alterar relações sociais. }\end{array}$ \\
\hline Controle cultural por meio de padrões de conduta. & $\begin{array}{l}\text { Aceitação da diversidade e celebração das } \\
\text { particularidades. }\end{array}$ \\
\hline $\begin{array}{l}\text { Controle formal via supervisão e conformidade com } \\
\text { normas e padrões. }\end{array}$ & $\begin{array}{l}\text { Controle por meio da combinação de avaliação da } \\
\text { eficiência com controle social. }\end{array}$ \\
\hline $\begin{array}{l}\text { Avaliação auto-referida a metas e normas definidas } \\
\text { internamente. }\end{array}$ & $\begin{array}{l}\text { Avaliação referida a expectativas dos usuários e dos } \\
\text { parceiros na rede. }\end{array}$ \\
\hline $\begin{array}{l}\text { Neutralidade tecnocrática - impessoalidade nos } \\
\text { julgamentos, autonomia da burocracia. }\end{array}$ & $\begin{array}{l}\text { Opção por valores claramente expressos, burocracia } \\
\text { militante ou cidadão profissional. }\end{array}$ \\
\hline Seleção com base na utilidade técnica. & $\begin{array}{l}\text { Seleção com base na utilidade técnica e perfil } \\
\text { adequado ao projeto. }\end{array}$ \\
\hline Líder como condutor. & Líder como mobilizador/articulador. \\
\hline $\begin{array}{l}\text { Motivação pela remuneração adequada e ascensão } \\
\text { na hierarquia (promoções). }\end{array}$ & $\begin{array}{l}\text { Motivação pela liberdade de implementar idéias e de } \\
\text { gratificar-se com seu sucesso. }\end{array}$ \\
\hline $\begin{array}{l}\text { O espírito de corpo como condição para a harmonia } \\
\text { e unidade, sendo mais produtivo que a discordância. }\end{array}$ & $\begin{array}{l}\text { A discordância em torno de idéias é fator de sucesso } \\
\text { no processo de mudança. }\end{array}$ \\
\hline Trabalho com base em recursos da organização. & $\begin{array}{l}\text { Trabalho com base em recursos dos membros da } \\
\text { rede. }\end{array}$ \\
\hline $\begin{array}{l}\text { Todos os fatores de produção precisam estar, } \\
\text { ordenadamente, em uma estrutura adequada. }\end{array}$ & $\begin{array}{l}\text { Os fatores de produção são continuamente } \\
\text { rearranjados. }\end{array}$ \\
\hline Localização espacial clara. & Localização espacial difusa. \\
\hline $\begin{array}{l}\text { Formalismo como estrutura de sobrevivência da } \\
\text { organização e da preservação de interesses. }\end{array}$ & $\begin{array}{l}\text { Formalismo como estratégia de mudança, de avançar } \\
\text { no tempo com relação a normas que paralisam } \\
\text { processos de mudança. }\end{array}$ \\
\hline $\begin{array}{l}\text { Definição dos usuários por critérios de custo- } \\
\text { benefício e/ou por pressões clientelistas. }\end{array}$ & $\begin{array}{l}\text { Direcionamento para grupos tradicionalmente não } \\
\text { atendidos pelo setor público, com ênfase em } \\
\text { aspectos de gênero, etnia, exclusão social. }\end{array}$ \\
\hline
\end{tabular}




\section{O Caso do Projeto de Saúde Mental de Belo Horizonte}

A experiência de Belo Horizonte ${ }^{(1)}$, MG, se inscreve no movimento por uma sociedade sem manicômios, lançado nacionalmente em 1987 por trabalhadores, familiares e usuários de serviços de saúde mental. Este movimento coloca para a sociedade não somente a crítica ao manicômio - espaço de exclusão e violência, mas ao modelo manicomial - paradigma de abordagem da loucura que não prescinde da distância e da separação. É esta radicalidade que orienta a estruturação do projeto, bem como as construções e articulações que se fazem necessárias para tratar os portadores de sofrimento mental, sem excluí-los e promovendo a sua inserção social.

Seus antecedentes históricos mais distantes se vinculam a um movimento social, o Movimento dos Trabalhadores em Saúde Mental (MTSM), que começa a tomar corpo em diversos locais do Brasil no final da década de 70. No período 1983-1987, lideranças do movimento ocupam a direção da assistência em saúde mental dos hospitais públicos (um hospital psiquiátrico e outros hospitais gerais) ligados ao Governo do Estado de Minas Gerais. Segundo um destes líderes (Campos, 1999), tal período pode ser caracterizado como um momento difícil, de desgarramento das origens, sendo enfatizada a humanização dos hospitais. Parte das dificuldades são creditadas à própria origem dos profissionais envolvidos que, apesar do discurso progressista, carregavam "restos do modelo de compreensão da realidade, sustentado pelos conceitos da 'boa forma' e da 'normalização', que impediam a radicalização da crítica e das ações”.

Apesar destas dificuldades, começa a se gerar, dentro do Hospital Psiquiátrico Galba Velloso, a reflexão sobre a prática, as conseqüências sociais, a perspectiva futura. Também resulta deste processo um grande contingente de novos Trabalhadores de Saúde Mental dispostos a envolver-se com o movimento pelo desmonte dos manicômios.

Em nível nacional, o movimento seguia absorvido por trabalhos locais e aproveitando os congressos nacional e estadual de psiquiatria para reunir-se. Em 1987 o Ministério da Saúde convoca uma Conferência Nacional de Saúde Mental, onde foi criada a Comissão Nacional dos Trabalhadores de Saúde Mental. Foi em uma reunião desta comissão, ainda em 1987, que surgiu a proposta de radicalização do movimento e o lema "Por uma Sociedade sem Manicômios". Em um encontro nacional, no final deste ano, a proposta foi aprovada e o dia 18 de maio instituído como Dia Nacional da Luta Antimanicomial; o movimento também ganha uma identidade mais clara, com a sua nomeação como Movimento da Luta Antimanicomial. 
“A partir daí, cada vez mais, uma pergunta apertava as nossas gargantas: Se tivéssemos poder político/financeiro neste momento, como organizaríamos os serviços e quais os saberes que sustentariam a nossa prática?” A busca a esta resposta se realiza em seminários dos Trabalhadores de Saúde Mental de vários locais do país, que apontam para a construção de redes substitutivas de atenção, para teorias e técnicas que dariam suporte às práticas inovadoras, para a construção, no longo prazo, de uma cultura antimanicomial, como parte de uma sociedade em que as diferenças teriam lugar (Campos, 1999, p. 7).

A criação do Sistema Único de Saúde (SUS), em 1988, tendo como estratégia dominante a descentralização, torna os municípios espaços privilegiados para realizar experiências substitutivas do modelo manicomial. Assim, a gestão municipal de Belo Horizonte, no período 1993-1996, se constitui em local para a construção do modelo substitutivo. Em 1992 também se constitui o Fórum Mineiro de Saúde Mental e, em 1994, a Associação dos Usuários de Saúde Mental de Minas Gerais (ASSUSSAM), importantes parceiros da sociedade na construção da rede alternativa e nas inovações promovidas em Belo Horizonte, que continuaram a evoluir no mandato seguinte do Governo Municipal.

Assim, o Projeto de Saúde Mental de Belo Horizonte, que começa a ser implantado a partir de 1993, oferece recursos assistenciais que se diferenciam do modelo manicomial hegemônico, partindo da premissa de que é possível, técnica e eticamente, tratar os loucos sem excluí-los; que para tratar a loucura é preciso reconhecê-la como parte integrante da experiência humana, tendo, portanto, uma significação que diz respeito à vida. Desta forma, é estruturada uma rede de atenção, com diferentes níveis de complexidade e diferentes funções, que acolhe o paciente na crise e constrói um vínculo para o seu acompanhamento continuado, e uma rede de suporte social que busca a inserção dos usuários. A rede de atenção é composta pelos Centros de Referência em Saúde Mental (CERSAMs), cuja função é acolher o paciente no momento da crise, atravessando-a com ele e seus familiares, até a estabilização; Unidades Básicas de Saúde, com equipes de saúde mental para acompanhar os pacientes estabilizados; um Centro de Referência para a Infância e Adolescência (CRIA) e Centros de Convivência. O projeto inclui ainda a construção de Lares Abrigados, Pensões Protegidas, Cooperativas de Trabalho e Empresas Sociais.

Além da atenção direta aos portadores de sofrimento mental, o projeto inclui atividades de controle e avaliação dos hospitais contratados pelo SUS, por meio da presença diária de supervisores que vêm forçando uma mudança na qualidade da assistência, tanto apurando eventuais irregularidades, quanto evitando a cronificação, buscando adequar o tempo de permanência no hospital aos fins exclusivamente terapêuticos. Os leitos psiquiátricos hospitalares foram reduzidos de 2.100 para 1.400 (Misoczky, 1999). 
O projeto conta com a intensa e constante participação dos dois movimentos sociais organizados acima mencionados - o Fórum Mineiro de Saúde Mental e a Associação de Usuários dos Serviços de Saúde Mental de Minas Gerais. Os usuários e seus familiares participam de assembléias regulares nos serviços, decidindo tanto sobre o seu funcionamento quanto sobre atividades de apoio ao desenvolvimento do projeto. $\mathrm{O}$ trabalho se efetiva por meio de uma rede composta por grande número de órgãos públicos, de organizações não governamentais e de instituições privadas.

Até que ponto o caso de Belo Horizonte configura uma formação políticoorganizacional?

. Não apenas o planejamento é feito de forma descentralizada, com a participação de executores e usuários, como a própria fonte e concepção do projeto têm origem nestes grupos, sendo que o espaço da Administração Pública é tomado, enquanto locus estratégico necessário para construir a viabilidade de uma imagem-objetivo, formulada em um movimento social, qual seja, a da construção de uma sociedade sem manicômios.

- A característica de um projeto que se constrói na medida em que se implementa, tendo em vista a necessidade de revisar a própria formação dos profissionais envolvidos e de formular uma nova concepção teórica e prática dos instrumentos de intervenção, torna inviável a sua implementação por meio de estruturas hierárquicas rígidas. No caso abordado, o contexto histórico social é determinante da natureza do projeto, sendo este moldado centralmente, em torno de uma ética substantiva e de uma utopia dirigida aos interesses dos usuários e seus familiares.

. Sendo um projeto que se constrói pela experimentação, não se baseia em ações padronizadas, papéis e normas, embora princípios da clínica médica sejam, principalmente no atendimento da urgência, uma forma de padronização que se preserva, sendo essencial para o enfrentamento desta situação.

. A divisão do trabalho que se encontra em serviços de saúde, até mesmo nos manicômios e clínicas psiquiátricas, se dilui em grande medida, já que a base do trabalho é interdisciplinar, mantendo-se apenas a prescrição de drogas como atividade exclusiva do médico. No restante das tarefas, existe grande compartilhamento e flexibilidade.

. A própria característica do projeto demanda ações intersetoriais, que ocorrem em todas as etapas do processo. 
. A meta certamente é a mudança. Neste caso, há alterações não apenas nas características dos serviços, mas também nas relações sociais do contexto em que eles são implementados.

. Esta mudança nas relações sociais passa pelo reconhecimento das diversidades e pela celebração das particularidades, buscando a concretização, nos serviços e na cidade, de uma cultura que respeite e aceite as diferenças como fundamentais para uma convivência democrática.

. O controle se processa mediante a avaliação de indicadores diretamente envolvidos com a natureza da atenção oferecida, como redução no número das internações, número de pacientes estabilizados ou número de pacientes que retornam a suas famílias ou a atividades na sociedade. Mas a avaliação também se faz por indicadores de natureza subjetiva, como a reação, na avenida principal da cidade, a um desfile dos portadores de sofrimento mental na sua Escola de Samba; ou como a reação dos moradores de uma bairro de classe média (Pampulha) à instalação de um CERSAM; ou, ainda, como nas declarações que os familiares e pacientes fazem sobre o impacto que o projeto está tendo sobre suas vidas.

- Da mesma forma, a reação dos parceiros na rede, tanto públicos como privados, é vital para que o projeto avance, transformando-se em referência importante para a sua avaliação.

. Os valores que pautam o projeto são os da pessoalidade, contrariando frontalmente o princípio da neutralidade tecnocrática. Os Trabalhadores de Saúde Mental, envolvidos na execução das atividades, são claramente uma burocracia militante, que alia o trabalho, enquanto condição necessária para a subsistência, com a ação política de provocar mudanças.

- A seleção dos trabalhadores alia as condições técnicas para execução das tarefas à condição necessária de um perfil adequado ao projeto.

- As lideranças exercem papel fundamental de articuladores e mobilizadores, não apenas dos que estão diretamente envolvidos com o projeto, mas também dos parceiros na rede e, em determinados momentos, de aliados transitórios, como os meios de comunicação ou empresas patrocinadoras.

. Os Trabalhadores de Saúde Mental, na medida em que se vinculam ao projeto pela sua concepção enquanto movimento social, se motivam pelo sucesso em provocar mudanças e pela conquista de maiores espaços de liberdade para avançar. 
- Os seminários e reuniões de trabalho nas diversas unidades do projeto, assim como os debates públicos, promovidos com os parceiros da rede e em favor deles, são importantes espaços para explicitar impasses e contradições em torno de diferentes formas de enfrentá-los; a discordância em torno de aspectos táticos, sem perder de vista a estratégia central, é fundamental para que essa seja bem sucedida.

. O trabalho se efetiva, centralmente, com o financiamento público, mas o aporte dos parceiros na rede é muito importante, seja via aporte direto de recursos, seja pela participação no trabalho conjunto.

- Os fatores de produção precisam estar ordenados de modo a oferecer suporte adequado ao desempenho técnico da equipe multiprofissional e, ao mesmo tempo, às necessidades dos pacientes; no entanto esta necessidade de uma rede de referência organizada não tem, aqui, a mesma característica que a concepção mecanicista presente na formação burocrático-tradicional, já que, pela própria natureza do projeto, estes fatores são potencial e necessariamente rearranjados com o avançar da reconstrução teórico-prática.

- A localização espacial é, simultaneamente, clara no que se refere à rede de serviços propriamente dita, e difusa no que se refere a situações como o atendimento nos locais em que os usuários se encontram, como no caso dos moradores de rua, ou como as atividades executadas por parceiros na rede, que trazem os usuários para o seu espaço, por exemplo, como no caso das salas de cinema ou das galerias de arte.

- O formalismo, enquanto maneira de desrespeitar, de modo consciente, normas e padrões, coloca-se como fator estratégico relevante, principalmente na relação da rede substitutiva com os níveis centrais do Governo Municipal, que manifestam um estranhamento, ainda que cada vez menor, à natureza essencialmente inovadora do projeto.

. O projeto se direciona para grupos que, embora de modo extremamente precário e ultrajante, eram atendidos pelo setor público. A mudança está em que, agora, o direcionamento não é mais para a exclusão, mas para a ampliação do reconhecimento de direitos e para a proteção de singularidades, para um processo de inclusão ativa.

Pelo que foi dito, o Projeto de Saúde Mental de Belo Horizonte se aproxima muito de uma formação político-organizacional, atendendo, em grande parte, aos atributos escolhidos para caracterizá-la, tendo em vista os objetivos deste estudo. Mesmo quando se preservam atributos da formação burocrático-tradicional, como fatores de produção precisos e localização espacial clara, estes se encontram articulados com seus pólos contraditórios: o rearranjo e a difusão. 


\section{O Caso do Orçamento Participativo de Porto Alegre}

O Orçamento Participativo(2) (OP), promovido pela Prefeitura Municipal de Porto Alegre, RS, “é uma modalidade de gestão pública [baseada na participação da população] nas diversas fases que compõem a elaboração e a execução [do orçamento municipal], especialmente na indicação de prioridades para a alocação de recursos de investimento" (Fedozzi, 1997, p. 105). Esta iniciativa parte da concepção de que seria possível alcançar um nível elevado de participação ativa da cidadania, produzindo uma tensão positiva entre burocracia e participação; e de um propósito de superação dos limites da democracia representativa com a presença sistemática dos cidadãos, não apenas no âmbito de consultas, mas também no de definição de demandas e de sua problematização (Laranjeiras, 1996).

O OP está assentado em estrutura e em processo de participação da população que se desenvolvem a partir de três princípios básicos: "regras universais de participação em instâncias institucionais regulares de funcionamento; um método objetivo de definição de recursos de investimento, que perfaz um ciclo anual de atividades públicas de orçamentação do município; e um processo decisório descentralizado, tendo por base a divisão da cidade em 16 regiões orçamentárias” (Fedozzi, 1997, p. 111).

Seus antecedentes históricos podem ser conhecidos pelo relato e análise de Fedozzi (1997), que propõe a distinção de quatro fases, conforme a evolução de três critérios técnico-políticos de planejamento participativo, quanto às modificações: na estrutura do OP, no que diz respeito às instâncias de tomada de decisão sobre os recursos públicos; na metodologia de distribuição dos recursos para investimento entre as regiões; no nível de participantes; e nos diversos estágios de interação política entre população, Executivo e Legislativo.

A primeira fase (1989 - orçamento de 1990) é marcada pela inexperiência dos novos dirigentes, pela frustração dos moradores com a falta de recursos e com a conseqüente crise na interação política da Prefeitura com a população. Inicialmente a discussão foi deflagrada, pela Prefeitura, de forma experimental e ocorreu por meio de consultas à população, em cinco regiões da cidade, em agosto de 1989. Nestas reuniões abertas a todos, foram indicados representantes, pelos moradores, para formarem uma comissão para acompanhar a elaboração do orçamento pela Secretaria de Planejamento Municipal. O estímulo à indicação de demandas pela comunidade não incluía nenhuma possibilidade de priorização; além disso, estas demandas representavam um déficit de equipamentos e serviços represados durante décadas de desenvolvimento excludente. O resultado foi um Plano de Obras sem condições de ser implementado, que gerou grandes 
conflitos, protestos e a descrença da população, levando a uma redução no número de participantes no ano seguinte.

A segunda fase (1990 - orçamento de 1991) representa os efeitos combinados da reforma tributária local e da desconcentração dos recursos promovidos pela Constituição de 1988 e, internamente, da discussão de concepções de planejamento estratégico e da criação de instâncias administrativas para implementar o OP.

Na terceira fase (orçamentos de 1992 e 1993) tornam-se nítidos os tipos de estrutura e de dinâmica processual que vinham sendo construídos; ocorre uma efetiva retomada da participação popular, com o aumento na credibilidade do processo em função dos investimentos efetivamente realizados desde 1990; ocorrem novas modificações na metodologia para distribuir os recursos, substituindo a concentração pela escolha de prioridades por setor de investimento. Esta fase consolida não apenas a estrutura do OP, mas também a dinâmica processual e as regras básicas do jogo. O Conselho do Orçamento Participativo, como síntese do processo participativo, alcança o reconhecimento interno na Prefeitura, ganhando também legitimidade em face dos movimentos comunitários das regiões como uma instância de mediação e de processamento das demandas prioritárias de investimento.

O início de um segundo mandato de governo (1993-1996), após a reeleição, marca a quarta fase, que se caracteriza pela complexificação de sua dinâmica e pelo contínuo crescimento do número de participantes. A criação das Plenárias Temáticas tornou mais heterogênea a representação social da participação, atraindo setores sociais plurais e grupos de interesse que até então não encontravam espaço em discussões de base exclusivamente regional. Nesta fase também foram modificadas a estrutura e a dinâmica de eleição dos delegados, com a criação de Fóruns de Delegados por região e em cada uma das Plenárias Temáticas.

Mas, afinal, até que ponto o caso do OP de Porto Alegre está resultando em uma formação político-organizacional na Prefeitura Municipal?

. Embora se identifiquem diversos centros de poder, a começar pelas Assembléias Regionais, passando pelas organizações autônomas da sociedade, pelo Conselho do Orçamento Participativo, até chegar às instâncias internas da Prefeitura que participam da coordenação dos procedimentos e, portanto, se possa dizer que ocorre planejamento descentralizado com a participação de usuários e executores, deve-se refletir com mais cuidado sobre o quanto um importante centro de poder, qual seja, o próprio Governo Executivo, está acumulando recursos de poder e enfraquecendo outros, em especial, o Poder Legislativo. Além disto, duas estruturas internas da Prefeitura, a Coordenadoria de Rela- 
ções com a Comunidade (CRC) e o Gabinete de Planejamento (GAPLAN), concentram muitos recursos de poder com relação ao restante do Governo Municipal, em função de se constituírem em organizadores da operacionalização do OP e de espaços pelos quais fluem as deliberações tomadas pelas suas instâncias para dentro dos órgãos que compõem a Administração.

. Ocorre um misto entre liderança centralizada e descentralizada, entre a orientação para o cumprimento de normas e a flexibilização das relações entre os participantes, ou seja, observa-se a presença de assessores ou funcionários da Prefeitura em todos os eventos que compõem a operacionalização do OP, mesmo aqueles organizados de forma autônoma, pela população, como na rodada intermediária. Além disto, é muito grande o peso das definições técnicas sobre o que é possível e o que não é possível demandar, incluindo a distribuição de um manual, elaborado pelos técnicos das diversas secretarias, ainda que aprovado anualmente pelo Conselho do OP, e que contém a lista de possibilidades em cada setor, disciplinando e normatizando as relações entre os participantes. Assim, dentro do possível, definido pelo Executivo, existe flexibilidade.

. Embora não exista Lei Municipal regulamentando o OP, a complexificação dos procedimentos tem levado a uma crescente definição de papéis e normas, ainda que auto-reguladas, isto é, revisadas e aprovadas anualmente pelo Conselho do OP.

. A divisão do trabalho entre os técnicos da Prefeitura se mantém, embora, em grande medida, esteja sendo reorganizada em função das tarefas a serem desempenhadas em um calendário pré-definido. Além disto, aqueles que são designados para acompanhar as reuniões do OP tiveram de agregar às suas funções anteriores uma atividade de caráter mais político. Sem dúvida tem havido, neste sentido, uma complexificação da tarefa. No entanto parece não ter havido flexibilização.

- A sistemática de definição das prioridades preserva e sedimenta, ainda mais, a setorialização, dificultando a reorganização da Administração Municipal em termos de planejamento e ação intersetorial.

- A meta é simultaneamente a manutenção e o crescimento (ou aprofundamento) do OP e a mudança, entendida enquanto alteração das relações sociais na cidade. O perfil dos participantes indica que a população com condições socioeconômicas mais desfavoráveis se tem apropriado deste espaço de participação e, por meio dele, obteve alguma melhoria nestas condições.

. Existe dificuldades em incorporar demandas vinculadas a alguns grupos sociais excluídos - como moradores de rua, usuários de drogas, portadores de sofri- 
mento mental, na medida em que o processo privilegia aqueles com capacidade de organização e de vocalização de suas demandas. As Plenárias Temáticas, na prática, não se têm constituído em espaço para superar esta restrição, já que são apropriadas por profissionais do setor. Assim, um albergue para moradores de rua é demanda de quem? A implicação desta restrição é que se reforçam as organizações de tipo mais convencional (associações de moradores, grupos ligados às igrejas etc.), em detrimento da incorporação das diferenças e das particularidades.

- O controle se dá, predominantemente, pelo controle social, embora também se evidenciem ganhos de eficiência na gestão dos recursos públicos.

. A avaliação é predominantemente referida às expectativas da população.

. Os procedimentos, aparentemente, rompem com a impessoalidade e com a autonomização da burocracia, na medida em que os técnicos precisam defender seus critérios nas reuniões com a população. Além disto, quando uma secretaria tem um projeto que quer ver implementado, os técnicos precisam comparecer às assembléias, disputar e convencer a população a incluí-lo entre as suas prioridades. Por outro lado, o peso da normatização técnica sobre o que é possível demandar, como já foi referido, neutraliza em boa medida essa ruptura, podendo caracterizar-se como outra forma de autonomização e de proteção para a impessoalidade.

. Os assessores e funcionários diretamente envolvidos com a coordenação do OP manifestam um caráter de militância e possuem uma crença, de caráter claramente ideológico, nas virtudes democratizadoras do processo. No entanto o mesmo não se pode dizer do conjunto de funcionários da Prefeitura. Existem dois grandes grupos, a burocracia militante e a burocracia que se preserva sob a capa da neutralidade técnica e da impessoalidade, como que esperando para ver até onde isto tudo vai e no que resultará.

. Os assessores e funcionários diretamente envolvidos com a coordenação do OP são escolhidos principalmente por seu perfil e adesão ao processo, sendo, na sua maioria, cargos de confiança do Executivo.

- As lideranças constituem um misto de condutor e de mobilizador/articulador.

- A motivação é, certamente, pela gratificação com o sucesso, até mesmo considerando o sucesso nas eleições como fator motivador importante.

. Existe harmonia e unidade entre assessores e funcionários envolvidos diretamente com o OP, embora esta se deva menos ao espírito de corpo e mais à coesão ideológica, como já foi mencionado. 
. O trabalho se executa principalmente com base nos recursos da organização.

. Os fatores de produção, como meios para que os procedimentos ocorram, são ordenados em uma estrutura, com pouco espaço para rearranjos no meio do processo. Mesmo as Assembléias Gerais da primeira rodada, com grande freqüência de pessoas, são extremamente ordenadas, com número fechado de inscrições, com tempo para a intervenções, com roteiro cumprido à risca, com a manifestação do Prefeito ou do seu representante sendo a última.

- A localização espacial é clara, ainda que descentralizada nas regiões e microrregiões.

. O formalismo não parece característica importante do processo.

. O OP está direcionado para grupos sociais que, de outra forma, não teriam acesso a espaços de decisão sobre obras na cidade.

Embora incorporando alguns aspectos da formação político-organizacional, o caso do OP mostra que é possível criar instâncias de participação da população, sem que isto implique inovações importantes nas características internas de organização da Administração Pública; verifica-se, pelo contrário, crescente disciplinamento desta participação segundo a lógica predominante de uma formação burocrático-tradicional.

\section{Considerações Finais}

Ambos os casos representam experiências reconhecidas de ampliação da participação da população em processos de decisão e de ampliação de direitos sociais; um deles inova, ao desenvolver uma política inclusiva e democratizadora, que rompe com padrões de relações sociais pautadas pelo preconceito, estigmatização e exclusão, mesmo física; o outro inova, ao desenvolver uma política inclusiva e democratizadora, que rompe com padrões de relações sociais pautadas pelo clientelismo e patrimonialismo na definição do gasto público. Ambos incorporam a dimensão da cidadania ativa na gestão pública, valorizando as responsabilidades dos sujeitos com a comunidade em que vivem.

Portanto, nos termos do referencial utilizado neste estudo e considerando as relações do Governo Municipal com os membros da sua comunidade, ambos os casos constituem práticas inovadoras da Administração Pública, que vêem os cidadãos como membros plenos da sociedade, que têm acesso a direitos e os 
exercem; incluem o controle social sobre a gestão, por meio de espaços de debate amplo e informado; estabelecem pontes entre o Estado e a sociedade civil.

No entanto, no caso da rede substitutiva de serviços de atenção à saúde mental de Belo Horizonte, as relações entre cidadania ativa e administração municipal estão configurando um perfil inovador no nível intra-organizacional. Já no caso do OP de Porto Alegre esta não é a tendência predominante.

Como foi descrito, uma importante diferença entre os dois casos está na sua origem. O caso de Belo Horizonte se origina em movimento social que ocupa o espaço público, enquanto estratégia de construção de um projeto que envolve mudanças na sociedade, e não apenas na gestão pública. Este movimento social apresenta, simultaneamente, as três formas de reação mencionadas por SchererWarren (1999): a denúncia e a explicitação de conflitos; a construção de uma utopia transformadora, com a criação de projetos alternativos; a cooperação e as parcerias para a resolução de problemas sociais. Preserva, transpondo-as para dentro da Administração Pública, as três dimensões: contestadora, propositiva e solidarística. O caso de Porto Alegre se origina no seio do Governo Municipal como iniciativa que, nos seus primeiros momentos, parece ter sido uma forma de construir a viabilidade do próprio governo em contexto político, social e econômico muito adverso. Desde o seu início apresenta as características de um processo do tipo incremental disjunto, em que o tomador de decisão aprende com a experiência e inclui o ajuste político, escolhendo simultaneamente meios e fins (Braybrooke e Lindblom, 1972).

Daí decorre outra diferença. Em Belo Horizonte o projeto se inscreve na construção de uma imagem-objetivo de longo prazo. Já, em Porto Alegre, uma estratégia para viabilizar a participação popular no planejamento substitui o planejamento estratégico de governo, com riscos para a governabilidade no médio e longo prazo, ou seja, em Porto Alegre, Planos de Investimentos Anuais, com origem em demandas imediatistas e fragmentadas dos setores que participam do processo, dão, na prática, a direção do governo e da cidade em construção.

Destas diferenças fundadoras podem derivar as diferenças na configuração resultante. Assim, o Projeto de Saúde Mental está instituindo serviços públicos com intensa articulação com os membros da rede que dá suporte à luta antimanicomial, tanto aqueles que se vinculam diretamente ao movimento, como aqueles que vêm sendo conquistados ao longo do caminho, e configurando uma formação político-organizacional, que pode constituir importante referência para práticas inovadoras na gestão pública. Já o Orçamento Participativo tem percorrido o caminho inverso, submetendo, em grande medida, à lógica da formação burocrático-tradicional práticas inovadoras que podem estar ocorrendo na organização dos movimentos sociais. 
Nesse sentido, o OP disciplina as disputas de interesse entre grupos da sociedade, utilizando formas objetivas, como a pontuação mediante critérios quantificáveis. Ao mesmo tempo, as instâncias do OP se legitimam como os únicos canais para reinvindicações sociais sobre equipamentos urbanos e políticas sociais. Desta forma, a dimensão contestadora dos movimentos sociais (Castells, 1972, 1978) se esvazia. Além disto, o princípio da autonomia das organizações da população fica seriamente comprometido.

Apesar dessas limitações, um aspecto interessante no caso de Porto Alegre é que o OP propicia espaços de difusão de informações sobre a Administração e de como esta se estrutura, que leis e regras segue (como nos processos de licitação, por exemplo), levando a níveis crescentes de apropriação da coisa pública pela população. Pode ser que, desta forma, se estejam criando condições para reverter a predominância da lógica da formação burocrático-tradicional, com a possibilidade de um controle crescente da população sobre a Administração Pública, bem como para "novas pautas de interação social que assegurem a resolução efetiva de problemas de ação coletiva, junto com condições para a deliberação pública, de modo que favoreçam a cooperação e a solidariedade” (Grau, 1997, p. 255).

Outro aspecto interessante deste caso é que, ao abrir canais de comunicação entre a Administração e a população, provocou um esvaziamento do papel desempenhado por vereadores como agenciadores de clientela junto ao Poder Público. Tal resultado acabou por originar certo clima de confronto entre grande parte dos vereadores e setores do movimento comunitário (Laranjeira, 1996). Em grande medida, parece haver sobreposição das atribuições do Conselho do OP e da Câmara de Vereadores, que ainda está por ser resolvida. Uma tendência parece ser a mudança no perfil dos vereadores que, nas últimas eleições, deixam de ter uma base regional e passam a representar grupos de interesse (mulheres, negros, religiões etc.) ou a incluir personalidades (radialistas ou dirigentes de clubes de futebol, por exemplo).

Uma constatação interessante deste estudo é a não existência de relação direta e automática entre inovação nas relações entre Administração Pública e população e inovação no interior das estruturas e práticas de governo. Embora se reconheça a importância da primeira, não é possível prescindir da segunda, já que a persistência de padrões da formação burocrático-tradicional impõe limites aos avanços da democratização e das próprias políticas sociais inclusivas. 


\title{
Notas
}

\begin{abstract}
${ }^{1}$ Esta experiência de gestão foi premiada no ciclo de 1998 do Programa Gestão Pública e Cidadania Programa FGV-Fundação Ford.

${ }^{2}$ Esta experiência foi destaque no Habitat de 1996, sendo reconhecida internacionalmente, até mesmo pelas Nações Unidas e pelo Banco Mundial. No Brasil existe hoje mais de 70 experiências influenciadas pela iniciativa de Porto Alegre, em municípios administrados pelos mais diversos partidos políticos. No Estado do Rio Grande do Sul também se desenvolve uma experiência de OP. A dissertação de mestrado de Fedozzi (1997) serviu como importante referência para a elaboração deste item.
\end{abstract}

\section{Referências Bibliográficas}

ARENDT, $\mathrm{H}$.

O que é política? Fragmentos das obras póstumas compiladas por Ursula Ludz. Rio de Janeiro: Bertrand Brasil, 1998.

AZEVEDO, S. de; ANDRADE, L. A. G. de.

A reforma do estado e a questão federalista: reflexões sobre a proposta Bresser Pereira. In: DINIZ, E.; AZEVEDO, S. de. (Orgs.). Reforma do estado e democracia no Brasil. Brasília: ENAP/UNB, 1997.

BOJE, D.;

DENNEHY, R. F.

Managing in the postmodern world: America's revolution against exploitation. Iowa: Kendall/ Hunt, 1993.
BRAYBROOKE, D.; LINDBLOM, C. E.

Uma estratégia de decisão social: escolha de políticas alternativas como processo social. Rio de Janeiro: Zahar, 1972.

CAMPOS, F.

Depoimento em Metipolá. Revista do CERSAM LESTE, 1999.

CASTELLS, M.

La questión urbana. Madrid: Siglo XXI, 1972.

City, class and power. London: MacMillan, 1978.

CLEGG, S. R.

Modern organizations:

organizations studies in the postmodern world. London: Sage Publications, 1990. 
COOPER, R.;

BURRELL, G.

Modernism, postmodernism and organizational analysis: an introduction. Organization

Studies, v. 9, n. 1, p. 91-112, 1988.

DINIZ, E.

Governabilidade, democracia e reforma do estado: os desafios da construção de uma nova ordem no Brasil dos anos 90. In: DINIZ, E.; AZEVEDO, S. de. (Orgs.). Reforma do estado e democracia no Brasil. Brasília: ENAP/UNB, 1997.

FARAH, M. F. S.

Reforma de políticas sociais no Brasil: experiências recentes de governos subnacionais. Revista de Administração, v. 33, n. 1, p. 51-59, jan./mar. 1998.

FAYOL, H.

Administração industrial e geral. São Paulo: Atlas, 1954.

FEDOZZI, L.

Orçamento participativo: reflexões sobre a experiência de Porto Alegre. Porto Alegre: FASE/ IPPUR/Tomo Editorial, 1997.

FERNÁNDEZ, P. P.;

BARRIENTOS, A. V.

Democratización de la gestión municipal y ciudadania de las mujeres: sistematización de experiencias innovadoras.

Disponível em: <http:// www.iigov.org/iigov/pnud/bibliote/ paper/p060600m.htl> Acesso em: 13 jun. 2000.

FISCHER, T.

Gestão contemporânea, cidades estratégicas: aprendendo com fragmentos e reconfigurações do local. In: FISCHER, T. (Org.). Gestão contemporânea: cidades estratégicas e organizações locais. Rio de Janeiro: Editora da FGV, 1997.

GRAU, N. C.

Repensando el público a través de la sociedad: nuevas formas de gestión pública y representación social. Caracas: CLAD/Nueva Sociedad, 1997.

GUERREIRO RAMOS, A. Administração e contexto brasileiro: esboço de uma teoria geral da administração. Rio de Janeiro: Editora da FGV, 1983.

HAGGARD, S.;

KAUFMAN, R.

$\mathrm{O}$ estado no processo de iniciação e consolidação de reformas orientadas para o mercado. In: SOLA, L. (Org.). Estado, mercado e democracia: política e economia comparada. São Paulo: Paz e Terra, 1993.

HELLER, A.; FÉHER, F.

A condição política pós-moderna. Rio de Janeiro: Civilização Brasileira, 1998. 
INOJOSA, R. M.

Intersetorialidade e a configuração de um novo paradigma organizacional. Revista de Administração Pública, v. 32, n. 2, p. 35-48, mar./abr. 1998.

JUNQUEIRA, L. A. P.;

INOJOSA, R. M.;

KOMATSU, S.

Descentralização e intersetorialidade na gestão pública municipal no Brasil: a experiência de Fortaleza. Caracas: UNESCO/CLAD, 1998. Série Concurso de Ensayos CLAD.

KING, C. S.;

ATIVERS, C.

Government is us: public administration in an antigovernment era. London: Sage Publications, 1998.

\section{LARANJEIRA, S. G.}

Gestão pública e participação: a experiência do Orçamento Participativo em Porto Alegre. São Paulo em Perspectiva, v. 10, n. 3, p. 129-137, 1996.

LOIOLA, E.; MOURA, S.

Análise de redes: uma contribuição aos estudos organizacionais. In: FISCHER, T. (Org.). Gestão contemporânea: cidades estratégicas e organizações locais. Rio de Janeiro: Editora da FGV, 1997.
MATUS, C.

Chimpanzé, Maquiavel e Ghandi: estratégias políticas. São Paulo: FUNDAP, 1996.

MISOCZKY, M. C.

O Projeto de Saúde Mental de Belo Horizonte: admitir que a loucura existe cria uma realidade. In: FUJIWARA, L. M.; ALESSIO, N. L. N.; FARAH, M. F. S. (Orgs.). 20 experiências de gestão pública e cidadania. São Paulo: FGV/Fundação Ford, 1999.

MOTTA, P. R.

Transformação organizacional: a teoria e a prática de inovar. Rio de Janeiro: Qualitymark, 1998.

SANTOS, B. de S.

Pela mão de Alice: o social e o político na pós-modernidade. São Paulo: Cortez, 1995.

A reinvenção solidária e participativa do estado. Trabalho apresentado no Seminário Sociedade e Reforma do Estado, MARE, abr. 1998. mimeo.

SANTOS, W. G. dos.

Governabilidade, sociedade civil e reforma do estado. Trabalho apresentado no Seminário Governo e Pobreza, IUPERJ/ URBANDATA/Universidade de Toronto/Fundação Ford, jun. 1994. mimeo. 
SCHACHTER, H. L.

Reinventing government or reinventing ourselves: the role of citizen owners in making a better government. Albany: State University of New York Press, 1997.

SCHERER-WARREN, I.

Cidadania sem fronteiras: ações coletivas na era da globalização. São Paulo: HUCITEC, 1999.

SOARES, J. A.;

GONDIM, L.

Novos modelos de gestão: lições que vêm do poder local. In: SOARES, J. A.; CACCIA-BAVA, S. (Orgs.). Os desafios da gestão municipal democrática. São Paulo: Cortez, 1998.

\section{TENDLER, J.}

Bom governo nos trópicos: uma visão crítica. Brasília: ENAP/ Revan, 1998.

\section{THIELEMAN, G. S.}

A demand-side perspective on the importance of representative bureaucracy: AIDS, ethnicity, gender, and sexual orientation.

Public Administration Review, v. 56, n. 2, p. 168-173, 1997.

TURNER, B.

Outline of a theory of citizenship. Sociology, v. 24, n. 2, 1990.

WEBER, M.

Economia y sociedad. México:

Fondo de Cultura Económica, 1997. 